\title{
Estimativas de parâmetros genéticos para os escores visuais e suas associações com peso corporal em bovinos de corte ${ }^{1}$
}

\author{
William Koury Filho ${ }^{2}$, Lucia Galvão de Albuquerque ${ }^{3}$, Selma Forni ${ }^{4}$, Josineudson Augusto II \\ de Vasconcelos Silva ${ }^{5}$, Marcos Juniti Yokoo ${ }^{6}$, Maurício Mello de Alencar ${ }^{7}$ \\ ${ }^{1}$ Fonte de financiamento: CAPES, FAPESP e CNPq. \\ 2 Doutorando do Programa de Pós-Graduação em Zootecnia - FCAV - UNESP/Jaboticabal. BrasilComZ - Zootecnia Tropical, Jaboticabal, \\ SP. Bolsista CAPES. \\ ${ }^{3}$ Departamento de Zootecnia - FCAV - UNESP/Jaboticabal, SP. Bolsista CNPq. \\ ${ }^{4}$ Doutorando do Programa de Pós-Graduação em Zootecnia - FCAV - UNESP/Jaboticabal. Bolsista CNPq \\ 5 Pós - doutorando do Programa de Pós-Graduação em Genética e Melhoramento Animal-FCAV-UNESP/Jaboticabal. Bolsista do CNPq - Brasil. \\ ${ }^{6}$ Doutorando do Programa de Pós-Graduação em Genética e Melhoramento Animal - FCAV - UNESP/Jaboticabal. Bolsista da Fapesp. \\ ${ }^{7}$ Embrapa Pecuária Sudeste - São Carlos, SP. Bolsista CNPq.
}

RESUMO - Foram avaliados 27.523 e 21.746 registros das características conformação, precocidade e musculatura à desmana e ao sobreano, respectivamente, para estimar os componentes de covariância entre estas características e entre estas e os pesos corporais medidos nas mesmas idades. Para as análises dos dados, foram empregados modelos animais com efeitos genéticos direto e materno e efeito de ambiente permanente materno. Máxima verossimilhança restrita foi empregada para estimar os parâmetros genéticos. As estimativas de herdabilidade dos escores à desmama foram 0,$13 ; 0,25$ e 0,23 para conformação, precocidade e musculatura, respectivamente. As estimativas de herdabilidade dos escores visuais avaliados ao sobreano foram de maiores magnitudes $(0,24 ; 0,32$ e 0,27 para conformação, precocidade e musculatura, respectivamente). As estimativas das correlações genéticas entre escores medidos às mesmas idades, considerando desmana e sobreano, foram 0,67 e 0,75 entre conformação e precocidade; 0,61 e 0,71 entre conformação e musculatura; 0,95 e 0,95 entre precocidade e musculatura. As correlações genéticas estimadas entre o peso corporal à desmama e conformação, precocidade e musculatura, respectivamente, foram 0,$97 ; 0,67$ e 0,62 . As estimativas entre conformação, precocidade, musculatura ao sobreano e o peso corporal foram 0,$83 ; 0,59$ e 0,58 , respectivamente. Os resultados indicam que os escores visuais podem ser utilizados como critérios de seleção. Aumento nos pesos corporais deve ser esperado como resposta correlacionada à seleção para essas características.

Palavras-chave: avaliação visual, correlação genética, gado de corte, herdabilidade, Nelore, peso

\section{Genetic parameters estimates for visual scores and their association with body weight in beef cattle}

\begin{abstract}
It was evaluated 27,523 and 21,746 records on traits of conformation, finishing precocity and musculature measured at weaning and a year after weaning, respectively, for the estimation of (co)variance components among these traits, and between them and body weights at the same ages. The data were analyzed by employing an animal model with direct and maternal genetic effect and permanent maternal environment effect. Restricted maximum likelihood was employed for the estimation of genetic parameters. The heritability estimates of visual scores at weaning were 0.13 , 0.25, 0.23 for conformation, finishing precocity, and musculature respectively. The heritability estimates of visual scores one year after weaning were greater: $0.24,0.32$ and 0.27 for conformation, finishing precocity, and musculature, respectively. The genetic correlations estimates among scores at the same ages were: 0.67 and 0.75 between conformation and finishing precocity; 0.61 and 0.71 between conformation and musculature; 0.95 and 0.95 between finishing precocity and musculature, considering weaning and one year further, respectively. The genetic correlations estimated between weaning weight and conformation, finishing precocity, and musculature, were $0.97,0.67$ and 0.62 , respectively. The estimates among conformation, finishing precocity, musculature at year after weaning and body weight were 0.83 , 0.59 , 0.58 , respectively. The results indicated that the visual scores can be used as selection criteria. Body weight increases can be expected as a correlated response for selection of such traits.
\end{abstract}

Key Words: beef cattle, genetic correlations, heritability, Nelore, visual evaluation, weight 


\section{Introdução}

Uma importante ferramenta para aumentar a eficiência econômica dos rebanhos é a utilização de avaliações genéticas, que permitem a identificação e seleção dos indivíduos geneticamente superiores. O uso de animais geneticamente superiores como reprodutores aumenta de maneira cumulativa a frequência de genes desejáveis nos rebanhos e, consequentemente, a de fenótipos economicamente mais interessantes.

A implementação de programas de avaliação genética depende da escolha de critérios de seleção. Para isso, um ponto essencial na definição da viabilidade de uma característica como critério de seleção é o conhecimento de sua variabilidade genética, assim como de suas associações genéticas com outras características. Há vários estudos que abordam a estimação de componentes de covariância de características relacionadas ao crescimento de zebuínos (Mercadante et al., 1995). No entanto, são poucos os trabalhos que incluem avaliações dessas características porescores visuais, que é um processo relativamente simples e de pequeno custo.

As avaliações por escores visuais podem ser utilizadas para a seleção, pois permitem identificar animais com maior desenvolvimento ponderal e que, ao mesmo tempo, tenham melhor conformação morfológica, um eficiente indicativo de precocidade de acabamento (May et al., 1992; Campos \& Cardoso, 1995; Fries, 1996; Koury Filho, 2001). Há evidências de que características morfológicas apresentam respostas favoráveis à seleção.

Segundo Pons et al. (1989), após poucas décadas de seleção por escores visuais, animais da raça Hereford que acumulavam demasiada gordura, passaram a apresentar carcaças mais magras e com maior valor comercial. Na raça Nelore, são encontradas estimativas de herdabilidade para os escores visuais de conformação, precocidade e musculatura, avaliados à desmama e ao sobreano, que variam de 0,09 a 0,39 (Eler et al., 1996; Koury Filho 2001; Van Melis et al., 2003; Forni et al., 2007).

Considerando a possibilidade de utilização de escores visuais na composição de índices de seleção, realizou-se este estudo para estimação dos componentes de covariâncias entre as características conformação, precocidade e musculatura medidas à desmama e ao sobreano e entre estas e o peso corporal em animais da raça Nelore.

\section{Material e Métodos}

Foram analisadas as características conformação, precocidade e musculatura avaliadas por escores visuais e os pesos corporais à desmama e ao sobreano do arquivo zootécnico da Agropecuária Jacarezinho, situada em Valparaíso, noroeste do estado de São Paulo. A empresa atua na pecuária de corte nos segmentos de cria, recria e engorda, produz e comercializa animais para abate e reprodutores predominantemente da raça Nelore. Com área de 24.760 hectares, a empresa está dividida em duas fazendas: Jacarecatinga e Jacarezinho, com área total de 17.000 hectares de pastagens. Desta área, $60 \%$ são destinados às forrageiras: capim-colonião, capim-tanzânia e capim-mombaça, cultivares da espécie Panicum maximum Jacq. Os $40 \%$ restantes da área de pastagens são formados por braquiárias: Brachiaria decumbens, Brachiaria brizantha e Brachiaria ruziziensis. Os solos predominantes são os podzolizados (variação Lins-Marília). De acordo com dados fornecidos pela empresa, a precipitação média anual é de $1.261 \mathrm{~mm}$ e a temperatura média ao longo do ano, de $25^{\circ} \mathrm{C}$, com média mínima de $18^{\circ} \mathrm{C}$ e máxima de $30^{\circ} \mathrm{C}$.

Os animais são criados em pasto com suplementação mineral. Os controles zootécnicos e coleta de dados para avaliações genéticas são realizados ao nascimento, à desmama e ao sobreano. A estação de monta tem início na segunda quinzena do mês de novembro e dura aproximadamente 70 dias. Para as novilhas com 16 a 18 meses de idade, é realizada uma estação de monta fora de época entre os meses de abril e maio e tem duração de aproximadamente 60 dias.

Para as avaliações visuais de conformação, precocidade e musculatura, foram atribuídos, por consenso entre três avaliadores, escores conceituais relativos ao grupo de manejo em escala de 1 a 5 , em que 5 é a melhor expressão da característica e 1 a pior. De acordo com Jorge Jr. et al. (2001), as características conformação, precocidade e musculatura são descritas como:

- conformação: avalia-se a quantidade de carne na carcaça. Os escores são atribuídos visualizando-se a carcaça quando o animal é abatido no momento da avaliação. Esta característica é influenciada pelo tamanho e pelo grau de musculosidade;

- precocidade: nota indicatica da capacidade do animal em atingir o grau de acabamento mínimo da carcaça com peso vivo não elevado. Maior profundidade de costelas, maior caixa toráxica, silhueta cheia, virilhas pesadas e em início de deposição de gordura subcutânea principalmente na base da cauda, são indicativos de maior precocidade de terminação. Animais altos, esguios e extremamente magros tendem a ser mais tardios;

- musculatura: avalia-se o desenvolvimento de massa muscular como um todo, observando-se pontos como antebraço, paleta, lombo, garupa e, principalmente, o traseiro. 
As pesagens foram realizadas após submeter os animais a jejum completo por 12 horas utilizando-se balança eletrônica. Os grupos contemporâneos à desmama foram definidos pelas variavéis: sexo, fazenda, mês e ano de nascimento, fazenda e grupo de manejo à desmama. Para a definição dos grupos contemporâneos ao sobreano, foram adicionadas as variavéis: fazenda e grupo de manejo ao sobreano. Foram retirados do arquivo original: animais com pai e mãe desconhecidos, filhos de vacas com mais de 16 anos de idade e indivíduos que não apresentavam as informações completas dos escores de conformação, precocidade e musculatura à desmama ou ao sobreano.

Não foram considerados nas análises os dados de animais pertencentes a grupos de contemporâneos com menos de quatro indivíduos e os dados de animais com pesos 3,5 desvios-padrão acima ou abaixo da média de seu grupo de contemporâneos. Após as análises de consistência, o arquivo final apresentou 27.523 animais com observações de conformação, precocidade, musculatura e peso à desmama, e 21.746 animais com observações de conformação, precocidade, musculatura e peso ao sobreano, filhos de 295 touros e 16.540 vacas (Tabela 1). A matriz de parentesco utilizada nas análises continha 48.573 animais.

Além do efeito classificatório de grupo contemporâneo, foram incluídos nas análises os efeitos de classe de idade da vaca ao parto e idade do animal (linear e quadrático) no momento da coleta. Nove classes de idade da vaca foram criadas de acordo com a frequência de partos; as classes de 1 a 7 correspondem às idades 2 a 8 anos, a classe 8 incluiu as vacas de 9 a 11 anos e na classe 9 foram agrupados animais com mais de 11 anos. O modelo empregado é expresso em forma matricial como:

$$
\mathrm{y}=\mathrm{Xb}+\mathrm{Z}_{1} \mathrm{a}+\mathrm{Z}_{2} \mathrm{~m}+\mathrm{Z}_{3} \mathrm{c}+\mathrm{e}
$$

em que: $\mathrm{y}=$ vetor das variáveis-dependentes (escores visuais e pesos); $\mathrm{X}=$ matriz de incidência dos efeitos fixos; $\mathrm{b}=$ vetor dos efeitos fixos (GC, CIVP e covariável IDC); $\mathrm{Z}_{1}=$ matriz de incidência dos efeitos genéticos aditivos diretos; $a=$ vetor dos valores genéticos aditivos diretos dos animais; $Z_{2}=$ matriz de incidência dos efeitos genéticos aditivos maternos (considerado somente nas análises de características medidas à desmama); $\mathrm{m}=$ vetor de valores genéticos aditivos maternos (considerado somente nas análises de características medidas à desmama); $\mathrm{Z}_{3}=$ matriz de incidência do efeito de ambiente permanente materno; $\mathrm{c}=$ vetor de efeito do ambiente permanente materno; $\mathrm{e}=$ vetor de efeitos residuais aleatórios.

Pressuposições: $\mathrm{E}(\mathrm{y})=\mathrm{Xb}, \mathrm{E}(\mathrm{a})=0, \mathrm{E}(\mathrm{m})=0, \mathrm{E}(\mathrm{c})=0$, $\mathrm{E}(\mathrm{e})=0$, e:

$$
\operatorname{Var}\left[\begin{array}{c}
\mathbf{a} \\
\mathbf{m} \\
\mathbf{c} \\
\mathbf{e}
\end{array}\right]=\left[\begin{array}{cccc}
\mathbf{G}_{\mathbf{a}} & 0 & 0 & 0 \\
0 & \mathbf{G}_{\mathbf{m}} & 0 & 0 \\
0 & 0 & \mathbf{C} & 0 \\
0 & 0 & 0 & \mathbf{R}
\end{array}\right]
$$

em que: $\mathbf{G}_{\mathrm{a}}=\mathbf{A} \sigma_{\mathrm{a}}^{2}, \mathrm{~A}=$ matriz de parentesco, $\sigma_{\mathrm{a}}^{2}=$ variância genética aditiva direta, $\mathbf{G}_{\mathrm{m}}=\mathbf{A} \sigma_{\mathrm{m}}^{2}, \sigma_{\mathrm{m}}^{2}=$ variância genética aditiva materna, $\mathbf{C}=\mathbf{I} \sigma_{\mathrm{c}}^{2}, \mathrm{I}=$ matrizidentidade, $\sigma_{\mathrm{c}}^{2}=$ variância do efeito de ambiente permanente materno; $\mathbf{R}=\mathbf{I} \sigma_{\mathrm{e}}^{2}, \sigma_{\mathrm{e}}^{2}=$ variância residual.

Nas análises das características medidas ao sobreano, o efeito genético materno não foi considerado. Além disso, as análises foram realizadas juntamente com o peso à desmama com o objetivo de reduzir os efeitos de pré-seleção. Os componentes de covariância foram estimados por máxima verossimilhança restrita utilizando-se o programa REMLF90 do pacote BLUPF90 (Misztal, 1999). As análises foram repetidas com diferentes valores iniciais para assegurar a convergência no máximo global, que foi considerada satisfatória quando a variância do logaritmo da função de verossimilhança foi menor ou igual a $10^{-11}$.

\begin{tabular}{|c|c|c|c|c|c|c|c|}
\hline Característica & Observações & Média & Mínima & Máxima & Desvio-padrão & $\begin{array}{l}\text { Coeficiente } \\
\text { de variação\% }\end{array}$ & $\begin{array}{c}\text { Grupos de } \\
\text { contemporâneos }\end{array}$ \\
\hline \multicolumn{8}{|l|}{ Desmama } \\
\hline Conformação & 27.523 & 3,15 & 1 & 5 & 0,87 & 27,69 & 851 \\
\hline Precocidade & 27.523 & 3,34 & 1 & 5 & 0,86 & 25,83 & 851 \\
\hline Musculatura & 27.523 & 3,11 & 1 & 5 & 0,90 & 29,01 & 851 \\
\hline Peso (kg) & 21.746 & 281,74 & 136 & 467 & 41,31 & 14,66 & 1247 \\
\hline Conformação & 21.746 & 3,16 & 1 & 5 & 0,84 & 26,63 & 1247 \\
\hline Musculatura & 21.746 & 3,00 & 1 & 5 & 0,87 & 29,09 & 1247 \\
\hline Idade (dias) & 21.746 & 517,62 & 413 & 655 & 39,05 & 7,55 & - \\
\hline
\end{tabular}

Tabela 1 - Peso, conformação, precocidade e musculatura à desmama e ao sobreano de bovinos de corte 


\section{Resultados e Discussão}

As estimativas de herdabilidade $\left(\mathrm{h}^{2}\right)$ para efeito genético direto das características precocidade, musculatura e peso à desmama foram semelhantes (Tabela 2), o que evidencia expectativas semelhantes de progresso genético pela seleção direta para os escores visuais e o peso nesta fase de crescimento. Entretanto, a estimativa de herdabilidade para conformação foi menor, portanto, menores ganhos genéticos devem ser esperados, em decorrência da seleção para esta característica (Tabela 2).

Os resultados obtidos para as características precocidade e musculatura neste estudo foram superiores aos encontrados por Cardoso et al. (1998), que, avaliando um rebanho da raça Santa Gertrudis, estimaram herdabilidade de 0,10 para conformação, 0,15 para precocidade e 0,11 para musculatura medidas à desmama. Cardoso et al. (2001) também relataram estimativas do coeficiente de herdabilidade menores em rebanhos da raça Angus: 0,18; 0,19 e 0,19 para conformação, precocidade e musculatura, respectivamente, à desmama. Em trabalho realizado com animais da raça Angus, Robinson et al. (1993) estimaram herdabilidade de 0,15 para musculatura medida à desmama. Entretanto, para animais da raça Nelore, Jorge Jr. (2002) estimou $\mathrm{h}^{2}$ de $0,33 \pm 0,02 ; 0,39 \pm 0,02$ e $0,34 \pm 0,02$ para conformação, precocidade e musculatura, respectivamente, à desmama.

Embora em vários trabalhos tenham sido relatadas correlações genéticas negativas entre os efeitos genéticos direto e materno, neste estudo, optou-se por fixar esta correlação em zero, uma vez que pesquisas têm apontado que a correlação negativa pode ser devida a problemas de estrutura dos dados e/ou efeitos não considerados no modelo (Robinson, 1996; Meyer, 1997).

A estimativa de herdabilidade materna para peso à desmama (Tabela 2) foi pouco superior aos valores relatados por Eler et al. (1995), Pereira et al. (2001) e Koury Filho et al. (2003), que obtiveram estimativas que variaram de 0,04 a 0,09 em trabalhos com rebanhos da raça Nelore. Para as características conformação, precocidade e musculatura à desmama, as estimativas de herdabilidade materna (Tabela 2) foram superiores aos resultados relatados por Jorge Jr. (2002); 0,01 para conformação e precocidade; 0,03 para musculatura. Apesar da pequena magnitude do efeito genético materno, o mesmo não pode ser desprezado no modelo utilizado para a análise das características peso, conformação, precocidade e musculatura à demama nas populações avaliadas. O emprego de modelos que não consideram os efeitos maternos para a avaliação de características medidas à desmama pode resultar em superestimação da variância genética aditiva direta e superestimação da herdabilidade para efeito direto (Eler et al., 1995; Meyer, 1992).

Ao sobreano os valores das estimativas de herdabilidade direta de conformação, precocidade e musculatura foram superiores aos das estimativas obtidas para os escores visuais à desmama (Tabela 3 ), o que também foi observado por Cardoso et al. (2004). As características conformação, precocidade e musculatura parecem seguir a mesma tendência da característica peso. Neste e em vários outros trabalhos, as estimativas de herdabilidade dessas característica foram superiores às relatadas à desmama (Koots et al., 1994; Albuquerque \& Meyer, 2001; Siqueira et al., 2003). A menor estimativa de herdabilidade da característica conformação nas duas idades avaliadas, comparativamente às características precocidade e musculatura, provavelmente se deve à sua definição mais subjetiva, que não identifica um tipo morfológico específico e confunde tamanho e musculosidade, permitindo diferentes interpretações pelos avaliadores.

As estimativas de herdabilidade para conformação, precocidade e musculatura ao sobreano estão próximas aos valores relatados por Eler et al. (1996) e Van Melis et al. (2003) para animais da raça Nelore, e com os resultados relatados por Cardoso et al. (2004) para animais da raça Angus. Entretanto, valores menores foram observados por

Tabela 2 - Valores médios dos componentes de variância e parâmetros genéticos para as características medidas à desmama obtidos em análises bicaracterísticas

\begin{tabular}{|c|c|c|c|c|c|c|c|c|}
\hline \multirow[b]{2}{*}{ Característica } & \multicolumn{4}{|c|}{ Componente de variância* } & \multicolumn{4}{|c|}{ Parâmetro genético** } \\
\hline & $\sigma_{a}^{2}$ & $\sigma_{m}^{2}$ & $\sigma_{c}^{2}$ & $\sigma_{e}^{2}$ & $\mathrm{~h}_{\mathrm{a}}^{2}$ & $\mathrm{~h}_{\mathrm{m}}^{2}$ & $c^{2}$ & $\mathrm{e}^{2}$ \\
\hline Peso & 63,110 & 31,271 & 38,361 & 142,520 & 0,23 & 0,11 & 0,14 & 0,52 \\
\hline Precocidade & 0,163 & 0,025 & 0,074 & 0,389 & 0,25 & 0,04 & 0,11 & 0,60 \\
\hline Musculatura & 0,162 & 0,040 & 0,092 & 0,405 & 0,23 & 0,06 & 0,13 & 0,58 \\
\hline
\end{tabular}

$* \sigma_{\mathrm{a}}^{2}=$ variância genética aditiva direta; $\sigma_{\mathrm{m}}^{2}=$ variância genética aditiva materna; $\sigma_{\mathrm{c}}^{2}=$ variância de ambiente permanente materno; $\sigma_{\mathrm{e}}^{2}=$ variância residual; ${ }^{* *} \mathrm{~h}_{\mathrm{a}}^{2}=$ coeficiente de herdabilidade direta; $\mathrm{h}_{\mathrm{m}}^{2}=$ coeficiente de herdabilidade materna; $\mathrm{c}^{2}=$ proporção da variância fenotípica devida ao efeito de ambiente permanente materno $\mathrm{e}^{2}=$ proporção da variância fenotípica devida aos efeitos residuais. 
Koury Filho (2001), que encontrou estimativas de herdabilidade iguais a 0,13 e 0,11 para conformação, 0,09 e 0,11 para precocidade e 0,16 e 0,18 para musculatura em análises bicaracterísticas com peso à desmama e ganho pós-desmama, respectivamente, na raça Nelore.

Para os escores visuais de conformação, precocidade e musculatura à desmama e ao sobreano, as estimativas de herdabilidade relatadas neste estudo corroboram a afirmativa de Cardoso et al. (2001) de que, embora com relativo grau de subjetividade, os escores visuais relacionados às características de carcaça, quando aplicados criteriosamente por avaliadores qualificados, podem ser utilizados para seleção direta em bovinos de corte.

As estimativas de herdabilidade direta para pesos à desmama e ao sobreano indicam possibilidades de progresso genético no uso dessas características como critérios de seleção e estão de acordo com resultados de trabalhos realizados com a raça Nelore (Eler et al., 1994; Eler et al., 1996; Boligon et al., 2009; Koury Filho et al., 2003; Siqueira et al., 2003) e com revisão realizada por Koots et al. (1994), que relataram média de herdabilidade de 0,27 $\pm 0,09$ e $0,40 \pm 0,12$, respectivamente, para peso à desmama e ao sobreano, em diversas raças bovinas. Uma vez que ambos os pesos apresentam potencial de resposta à seleção direta e estão geneticamente correlacionados, o uso do peso à desmama é uma alternativa para a redução de custos.

Neste trabalho, as frações das variâncias fenotípicas devidas ao efeito de ambiente permanente materno estimadas para as características conformação, precocidade e musculatura à desmama foram próximas aos valores relatados por Jorge Jr. (2002) e superiores àqueles estimados por Cardoso et al. (2001), que variaram de 0,08 a 0,09 para conformação, precocidade e musculatura, respectivamente. Os resultados com a raça Nelore obtidos neste estudo e por Jorge Jr. (2002) indicam que é importante a inclusão do ambiente permanente materno no modelo para avaliação dessas características medidas à desmama, mesmo quando o efeito genético materno está sendo considerado. As proporções das variâncias fenotípicas devidas aos efeitos de ambiente permanente materno ao sobreano foram inferiores aos valores relatados por Koury Filho (2001), que encontrou estimativas de 0,$14 ; 0,12$ e 0,18 , respectivamente, para conformação, precocidade e musculatura. Esses resultados indicam que os escores visuais ao sobreano sofrem pequena influência do ambiente materno, provavelmente devido ao efeito residual de sua influência até a desmama. $\mathrm{O}$ ambiente materno foi importante para estas características medidas à desmama, mas, à medida que essa fase se distancia, outros efeitos ambientais passam a ser mais importantes.

Em geral, as estimativas de correlação genética (Tabela 4) foram altas e, em ambas as idades, as características precocidade e musculatura apresentaram as maiores correlações $(0,95)$, o que também foi relatado por Jorge Jr. (2002) para a raça Nelore. Estimativas de correlações genéticas de magnitudes próximas às encontradas neste estudo foram relatadas por Cardoso et al. (2001) que, avaliando dados obtidos à desmama em rebanhos Angus, estimaram correlações genéticas de 0,91 entre conformação e precocidade; 0,89 entre conformação e musculatura; e de 0,91 entre precocidade e musculatura. Entretanto, Cardoso et al. (2004) encontraram diferentes resultados ao sobreano; a correlação genética estimada entre as características precocidade e musculatura ao sobreano foi menor $(0,80)$, seguida da correlação entre conformação e precocidade $(0,92)$ e da correlação entre conformação e musculatura $(0,94)$, de maior magnitude.

As correlações genéticas estimadas entre os mesmos escores em diferentes idades foram de alta magnitude, fato observado também entre o peso corporal à desmama e ao sobreano e que evidencia a associação genética entre os escores visuais avaliados à desmama e ao sobreano. Estimativas mais altas 0,99 foram encontradas por Cardoso et al. (2004) entre conformação à desmama e sobreano; 0,93 entre precocidade nas duas idades e 0,90 entre musculatura à desmama e musculatura ao sobreano. Estes autores concluíram que as medidas poderiam ser consideradas

Tabela 3 - Componentes de variância e parâmetros genéticos estimados para as características medidas ao sobreano (valores médios obtidos em análises tricaracterísticas)

\begin{tabular}{|c|c|c|c|c|c|c|}
\hline \multirow[b]{2}{*}{ Característica } & \multicolumn{3}{|c|}{ Componente de variância* } & \multicolumn{3}{|c|}{ Parâmetro genético ${ }^{* *}$} \\
\hline & $\sigma_{\mathrm{a}}^{2}$ & $\sigma_{c}^{2}$ & $\sigma_{\mathrm{e}}^{2}$ & $\mathrm{~h}_{\mathrm{a}}^{2}$ & $c^{2}$ & $\mathrm{e}^{2}$ \\
\hline Peso & 198,667 & 21,943 & 321,200 & 0,37 & 0,04 & 0,59 \\
\hline Precocidade & 0,212 & 0,016 & 0,430 & 0,32 & 0,03 & 0,65 \\
\hline Musculatura & 0,178 & 0,033 & 0,438 & 0,27 & 0,05 & 0,67 \\
\hline
\end{tabular}

${ }^{*} \sigma_{\mathrm{a}}^{2}=$ variância genética aditiva direta; $\sigma_{\mathrm{c}}^{2}=$ variância de ambiente permanente materno; $\sigma_{\mathrm{e}}^{2}=$ variância residual; ${ }^{* *} \mathrm{~h}_{\mathrm{a}}^{2}=$ coeficiente de herdabilidade direta; $\mathrm{c}^{2}=$ proporção da variância fenotípica devida ao efeito de ambiente permanente materno; $\mathrm{e}^{2}=$ proporção da variância fenotípica devida aos efeitos residuais. 
como mesma característica observada em duas fases do crescimento e sugeriram a coleta apenas no momento da desmama, no caso da raça Angus. Neste estudo, as correlações genéticas entre os escores visuais à desmama e ao sobreano também foram expressivas. Entretanto, parece precipitada a definição de um único momento para a avaliação dos animais, pois a medida na desmama é muito interessante, por não haver pré-seleção, e ao sobreno as características morfológicas podem ser mais bem avaliadas pelo potencial genético do indivíduo, sem grande influência de efeitos maternos.

$\mathrm{Na}$ discussão do uso de escores como critérios de seleção, as correlações entre escores e os pesos-padrão devem ser consideradas, uma vez que tradicionalmente os pesos são empregados como critérios de seleão. As correlações genéticas estimadas entre peso à desmama e os escores visuais à desmama variaram de moderadas a altas, evidenciando associação genética entre peso à desmama e os escores visuais na mesma fase de crescimento; principalmente entre peso à desmama e conformação. Esses resultados corroboram os de Jorge Jr. (2002) e Cardoso et al. (2001). Valores mais elevados de correlações genéticas foram relatados por Cardoso et al. (1998), que estudaram bovinos da raça Santa Gertrudis à desmama e estimaram correlação genética entre peso à desmama e conformação de 0,92 , precocidade 0,91 e musculatura 0,91 .

Conforme esperado, as correlações genéticas entre peso à desmama e as características de escores visuais ao sobreano foram positivas, porém de menores magnitudes. As estimativas de correlações genéticas entre peso ao sobreano e conformação, precocidade e musculatura ao sobreano (Tabela 4) seguiram as mesmas tendências da fase de desmama, o que indica grande associação genética entre essas características também nesta idade. Esses resultados são importantes, pois, segundo Koch et al. (1994), a seleção por um índice de $50 \%$ de peso à desmama e $50 \%$ de escore visual de musculatura resultou em maiores ganhos genéticos direto e materno para os pesos à desmama e ao sobreano em comparação à seleção exclusiva pelos pesos.

As altas correlações genéticas entre conformação e peso nas duas fases do crescimento indicam que essas características são determinadas, em grande parte, pelos mesmos genes. Esses resultados eram esperados, uma vez que a definição da característica conformação indica que os escores devem ser atribuídos de acordo com a estimativa visual do peso da carcaça que se espera obter no momento da avaliação. Correlações genéticas de altas magnitudes entre conformação e peso também foram relatadas por Cardoso et al. (2004). Todavia, Koury Filho (2001) estimou correlações genéticas entre conformação ao sobreano e ganho de peso pós-desmama de 0,31. Esse autor relatou estimativas de correlações genéticas 0,52 e 0,58 entre as características precocidade e musculatura, respectivamente, e o ganho de peso pós-desmama.

A partir dos resultados apresentados, é possível esperar que a população estudada responda à seleção direta pelas avaliações visuais. Os escores visuais podem ser utilizados para seleção de tipos morfológicos economicamente mais eficientes, evitando biotipos extremos, compactos ou tardios, como preconiza o sistema de avaliação Ankony (Long, 1973), que penaliza animais com excesso de gordura na carcaça. Entretanto, segundo Fries (1996), ao longo do tempo de sua aplicação no Rio Grande do Sul, os rebanhos se tornaram tardios em acabamento.

As estimativas de correlação entre os efeitos genéticos maternos foram muito altas, acima de 0,93 (Tabela 4), o que indica a possibilidade de que os mesmos genes sejam parcialmente responsáveis por esse efeito nas características estudadas. As estimativas de correlações de ambiente permanente materno foram altas para as características

Tabela 4 - Estimativas de correlações entre os efeitos genéticos diretos (acima da diagonal) e os efeitos genéticos maternos (abaixo da diagonal)

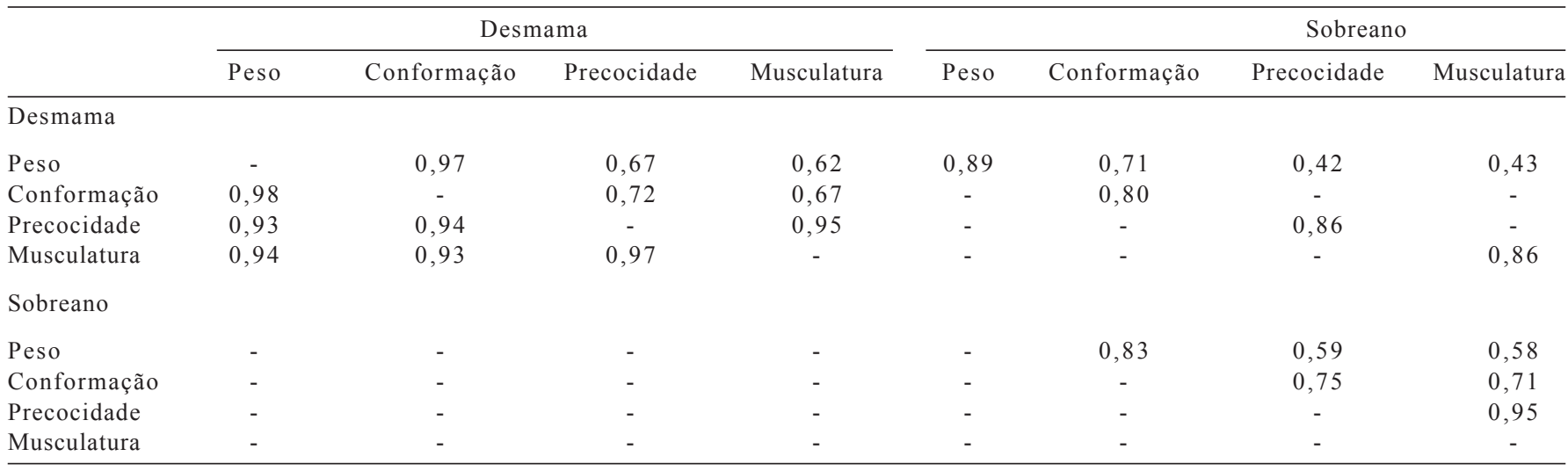


Tabela 5 - Estimativas de correlações entre os efeitos de ambiente permanente materno (acima da diagonal) e entre os efeitos residuais (abaixo da diagonal)

\begin{tabular}{|c|c|c|c|c|c|c|c|c|}
\hline & \multicolumn{4}{|c|}{ Desmama } & \multicolumn{4}{|c|}{ Sobreano } \\
\hline & Peso & Conformação & Precocidade & Musculatura & Peso & Conformação & Precocidade & Musculatura \\
\hline \multicolumn{9}{|l|}{ Desmama } \\
\hline Conformação & 0,60 & - & 0,98 & 0,98 & - & 0,64 & - & - \\
\hline Precocidade & 0,60 & 0,63 & - & 0,99 & - & - & 0,36 & - \\
\hline Musculatura & 0,57 & 0,62 & 0,72 & - & - & - & - & 0,34 \\
\hline Peso & 0,45 & - & - & - & - & 0,49 & 0,57 & 0,22 \\
\hline Confromação & 0,30 & 0,20 & - & - & 0,57 & - & 0,76 & 0,74 \\
\hline Precocidade & 0,24 & - & 0,16 & - & 0,54 & 0,63 & - & 0,82 \\
\hline Musculatura & 0,22 & - & - & 0,16 & 0,53 & 0,62 & 0,73 & - \\
\hline
\end{tabular}

avaliadas à desmama, e entre os pesos à desmama e ao sobreano (Tabela 5). Entretanto, entre o peso à desmama e os escores visuais ao sobreano e, entre os escores à desmama e ao sobreano, a magnitude das correlações entre ambiente permanente materno foi consideravelmente menor. Essas correlações são ainda menos expressivas entre os escores ao sobreano. As estimativas de correlações indicam que os escores visuais podem ser utilizados como critérios de seleção juntamente com os pesos corporais, e que ganhos genéticos em todos os critérios podem ser esperados.

É possível que a combinação de características de crescimento, como os pesos, e escores visuais em índices de seleção contribua para a escolha de indivíduos mais adaptados aos sistemas de produção em que estão sendo criados. Entretanto, segundo Forni et al. (2007), as características conformação, precocidade e musculatura sofrem grande influência do ambiente, de forma que respostas à seleção direta de pequenas magnitudes devem ser esperadas, e a predição de méritos genéticos acurados implicaria na necessidade de avaliação de progênies numerosas.

\section{Conclusões}

As características conformação, precocidade e musculatura, avaliadas por escores visuais, podem responder à seleção individual e promover ganhos genéticos. A seleção por essas características pode contribuir para a identificação de animais mais precoces. A seleção por um dos escores visuais provavelmente implicará em respostas correlacionadas positiva em todas os demais, na mesma ou em diferentes idades. Apesar das altas correlações genéticas dos escores em diferentes idades, a possibilidade de se utilizar apenas as medidas da desmama como critério de seleção ainda depende de estudos que considerem pesos econômicos.

\section{Referências}

ALBUQUERQUE L.G.; MEYER, K. Estimates of direct and maternal genetic effects for weights from birth to 600 days of age in Nelore cattle. Journal of Animal Breeding, v.118, p.83-92, 2001.

BOLIGON, A.A.; ALBUQUERQUE, L.G.; MERCADANTE, M.E.Z. et al. Herdabilidades e correlações entre pesos do nascimento à idade adulta em rebanhos da raça Nelore. Revista Brasileira de Zootecnia, v.38, n.12, p.2320-2326, 2009.

CAMPOS, L.T.; CARDOSO, F.F. Programa de melhoramento de bovinos de carne: manual do usuário. Pelotas: Associação Nacional de criadores, 1995. ("Herd Book Collares").

CARDoso, F.F.; CARDELlinO, R.A.; CAMPOS, L.T. Parâmetros genéticos para escores de avaliação visual à desmama em bovinos da raça Santa Gertrudis. In: REUNIÃO ANUAL DA SOCIEDADE BRASILEIRA DE ZOOTECNIA, 35., Botucatu, 1998. Anais... Botucatu: SBZ, 1998. v.3, p.506-508.

CARDoso, F.F.; CARDELlino, R.A.; CAMPOS, L.T. Componentes de (co)variância e parâmetros genéticos para caracteres produtivos à desmama de bezerros Angus criados no estado do Rio Grande do Sul. Revista Brasileira de Zootecnia, v.30, n.1, p.41-48, 2001.

CARDoso, F.F.; CARdellino, R.A.; CAMPOS, L.T. Componentes de (co)variância e parâmetros genéticos de caracteres pós-desmama em bovinos da raça Angus. Revista Brasileira de Zootecnia, v.33, n.2, p.313-319, 2004.

ELER, J.P.; FERRAZ, J.B.S.; LÔBO, R.B. et al. Genetic antagonism between growth and maternal ability in Nelore cattle. Revista Brasileira de Genética, v.17, p.59-64, 1994.

ELER, J.P.; VAN VLECK, L.D.; FERRAZ, J.B.S. et al. Estimation of variances due to direct and maternal effects for growth traits of Nelore cattle. Journal of Animal Science, v.73, n.1, p.3253-3258, 1995.

ELER, J.P.; FERRAZ, J.B.S.; SILVA, P.R. Parâmetros genéticos para peso, avaliação visual e circunferência escrotal na raça Nelore, estimados por modelo animal. Arquivo Brasileiro de Medicina Veterinária e Zootecnia, v.48, n.2, p.203-213, 1996.

FORNI, S.; FEDERICI, J.F.; ALBUQUERQUE, L.G. Tendências genéticas para escores visuais de conformação, precocidade e 
musculatura à desmama de bovinos Nelore. Revista Brasileira de Zootecnia, v.36, n.3, p.572-577, 2007.

FRIES, L.A. Uso de escores visuais em programas de seleção para a produtividade em gado de corte. In: SEMINÁRIO NACIONALREVISÃO DE CRITÉRIOS DE JULGAMENTO E SELEÇÃO EM GADO DE CORTE, 1., 1996, Uberaba. Anais... Uberaba: Associacao Brasileira de Criadores de Zebu, 1996. p.1-6.

JORGE JR., J.; PITA, F.V.C.; FRIES, L. et al. Influência de alguns fatores de ambiente sobre os escores de conformação, precocidade e musculatura à desmama em um rebanho da raça Nelore. Revista Brasileira de Zootecnia, v.30, p.1697-1703, 2001.

JORGE JR., J. Análise genética de escores de avaliações visuais e suas respectivas relações com desempenho ponderal na raça Nelore. 2002. 67f. Dissertação (Mestrado em Zootecnia - Genética e Melhoramento Animal) - Faculdade de Ciências Agrárias e Veterinárias, Jaboticabal.

KOCH, R.M.; CUNDIFF, L.V.; GREGORY, K.E. Cumulative selection and genetic change for weaning or yearling weight plus muscle score in Hereford cattle. Journal of Animal Science, v.72, p.864-885, 1994.

KOOTS, K.R., GIBSON, J.P., SMITH, C. et al. Analyses of published genetic parameters estimates for beef production traits. 1. Heritability. Animal Breeding Abstracts, v.62, p.309-338, 1994.

KOURY FILHO, W. Análise genética de escores de avaliações visuais e suas respectivas relações com desempenho ponderal na raça Nelore. 2001. 82f. Dissertação (Mestrado em Zootecnia) - Faculdade de Zootecnia e Engenharia de Alimentos, Pirassununga.

KOURY FILHO, W.; JUBILEU J.S.; ELER J.P. et al. Parâmetros genéticos para escores de umbigo e características de produção em bovinos da raça Nelore. Arquivo Brasileiro de Medicina Veterinária e Zootecnia, v.55, n.5, p.594-598, 2003.

LONG. R.L. El sistema de evaluación de Ankony y su aplicación en la mejora del ganado. Colorado: Ankony Corporation, 1973. 20p.

MAY, G.S.; MIES, W.L.; EDWARDS, J.W. et al. Effect of frame size, muscle score, and external fatness on live and carcass value of beef cattle. Journal of Animal Science, v.70, p.3311-3316, 1992 .
MERCADANTE, M.E.Z; LÔBO, R.B; BORGES, A.R. Parámetros genéticos para características de crecimiento en cebuinos de carne. Archivos Latinoamericanos de Producción Animal, v.3, p.45-69, 1995.

MEYER, K. Variance components due to direct and maternal effects for growth traits of Australian beef cattle. Livestock Production Science, v.31, p.179-204, 1992.

MEYER, K. Estimates of genetic parameters for weaning weight of beef cattle accounting for direct-maternal environment co variances. Livestock Production Science, v.52, p.187-199, 1997.

MISZTAL, I. Complex models, more data: simpler programming. In: COMPUTATIONAL CATTLE BREEDING WORKSHOP, 1999, Tuusala, Finland. Proceedings... Tuusala: Interbul, 1999. p.33-42.

PEREIRA, E.; ELER, J.P.; FERRAZ, J.B.S. Análise genética de algumas características reprodutivas e suas relações com o desempenho ponderal na raça Nelore. Arquivo Brasileiro de Medicina Veterinária e Zootecnia, v.53, n.6, p.720-727, 2001.

PONS, S.B.; MILAGRES, J.C.; TEIXEIRA, N.M. Efeitos de fatores genéticos e de ambiente sobre o crescimento e escores de conformação em bovinos da raça Hereford no Rio Grande do Sul I. Peso e escores de conformação à desmama. Revista Brasileira de Zootecnia, v.18, n.5, p.391-401, 1989.

ROBINSON, D.L.; HAMMOND, K.; McDONALD C.A. Live animal Measurement of carcass traits: estimation of genetic parameters for beef cattle. Journal of Animal Science, v.71, p.11281135, 1993.

ROBINSON, D.L. Models which might explain negative correlations between direct and maternal genetic effects. Livestock Production Science, v.45, p.111-122, 1996.

SIQUEIRA, R.L.P.G.; OLIVEIRA, J.A.; LÔBO, R.B. et al. Análise de variabilidade genética aditiva de características de crescimento na raça Nelore. Revista Brasileira de Zootecnia, v.32, n.1, p.99-105, 2003.

VAN MELIS, M.H.; ELER, J.P.; SILVA, J.A.V. et al. Estimação de parâmetros genéticos em bovinos de corte utilizando os métodos de máxima verossimilhança restrita e R. Revista Brasileira de Zootecnia, v.32, n.6, p.1624-1632, 2003. 